\title{
New Family of Logarithmic Lifetime Distributions
}

\author{
Said Hofan Alkarni \\ Department of Quantitative Analysis, King Saud University, Riyadh, Saudi Arabia
}

Received 2012-06-15, Revised 2012-11-21; Accepted 2012-12-20

\begin{abstract}
In this study a new lifetime class with decreasing failure rate is introduced by compounding truncated logarithmic distribution with any proper continuous lifetime distribution. The properties of the proposed class are discussed, including a formal proof of itsprobability density function, distribution function and explicit algebraic formulae for its reliability and failure rate functions. A simple EM-type algorithm for iteratively computing maximum likelihood estimates is presented. A formal equation for Fisher information matrix is derived in order to obtaining the asymptotic covariance matrix. Thisnew class of distributions generalizes several distributions which have been introduced and studied in the literature.
\end{abstract}

Keywords: Logarithmic Distribution, Decreasing Failure Rate, Lifetime Distributions

\section{INTRODUCTION}

Multi-parameter distributions to model lifetime data have been introduced by compounding a continuous lifetime and powerseries distributions. The Exponential Geometric (EG), Exponential Poisson (EP) and exponential logarithmic distributions were introduced and studied by Adamidis and Loukas (1998), Kus (2007) and Tahmasbi and Rezaei (2008), respectively. Recently, Chahkandi and Ganjali (2009) introduced the Exponential Power Series (EPS) distributions, which contain these distributions.

Situations where the failure rate function decreases with time have been reported by several authors. Indicative examples are business mortality (Lomax, 1954), failure in the air-conditioning equipment of a fleet of Boeing 720 aircrafts or in semiconductors from various lots combined (Proschan,1963) and the life of integrated circuit modules (Saunders and Myhre, 1983). In general, a population is expected to exhibit Decreasing Failure Rate (DFR) when its behavior over time is characterized by 'work hardening' (in engineering terms) or 'immunity' (in biological terms); sometimes the broader term 'infant mortality' is used to denote the DFR phenomenon. The resulting improvement of reliability with time might have occurred by means of actual physical changes that caused self-improvement or simply it might have been due to population heterogeneity. Indeed, Proschan (1963) provided that the DFR property is inherent to mixtures of distributions with constant failure rate (McNolty et al., 1980 for other properties of exponential mixtures) and Gleser (1989) demonstrated the converse for any gamma distribution with shape parameter less than one. In addition, Gurland and Sethuramm (1994) give examples illustrating that such results may hold for mixtures of distributions with rapidly increasing failure rate. A mixture of truncated geometric distribution and exponential with DFR was introduced. The Exponential-Poisson (EP) distribution proposed by Kus (2007) and genearalized by Hemmati et al. (2011) using Wiebull distribution and the exponential-logarithmic distribution discussed by Tahmasbi and Rezaei (2008). Silva et al. (2010) did a new distribution with decreasing, increasing and upside down bathtub failure rate. A two-parameter distribution family with decreasing failure rate arising by mixing power-series distribution has been introduced by Chahkandi and Ganjali (2009). A Weibull power series class of distributions with Poisson presented by Morais and Barreto-Souza (2011). Morais (2009) in a master degree thesis presented a class of generalized Beta distributions, Pareto power series and Weibull power series. Lately, Alkarni and Oraby (2012) obtained a class of truncated Poisson with any continuous lifetime distribution. 
A further exponentiated type distribution has been introduced and studied in the literature. The exponential weibull (EW) distribution was proposed by Mudholkar and Srivastava (1993) to extend the GE distribution. This distribution was also studied by Mudholkar et al. (1995); Mudholkar and Hutson (1996); Nassar and Eissa (2003). Nadarajah and Kotz (2006) introduced four more exponentiated type distributions: the exponentiated gamma, exponentiatedWeibull, exponentiatedGumbel and exponentiatedFréchet distributions by generalizing the gamma, Weibull, Gumbel and Fréchet distributions in the same way that the GE distribution extends the exponential distribution. Barreto-Souza and Cribari-Neto (2009) introduced the generalized exponential-Poisson distribution which extends the exponential-Poisson distribution in the same way that the GE distribution extends the exponential distribution.

In this study we generalize the work of Tahmasbi and Rezaei (2008) to a class of several lifetime continuous distributions and hence any mixture of continuous lifetime with truncated logarithmic distribution such as exponential, weibull, pareto becomes a special case of this class. This study is organized as follow. The new class of logarithmic lifetime distributions with its probability and distribution functions are introduced. The corresponding survival and hazard rate functions with some of their properties are derived. Maximum likelihood estimate of the unknown parameters are obtained based on arandom sample via EM algorithm. The entropy for the logarithmic lifetime distributions class is discussed.

\subsection{The Class}

Given $Z$, let $T_{1}, \ldots, T_{Z}$ be independent and identically distributed (iid) random variables with probability density function (pdf) given by:

$$
\mathrm{f}_{\mathrm{T}_{\mathrm{i}}}(\mathrm{x} ; \underline{\theta})=\mathrm{f}_{\mathrm{T}}(\mathrm{x} ; \underline{\theta}) ; \underline{\theta}=\left(\theta_{1}, \ldots, \theta_{\mathrm{k}}\right) \text { for, } \mathrm{k} \geq 1, \mathrm{x}, \underline{\theta} \in \square^{+}
$$

Here, $\mathrm{Z}$ is a zero truncated Logarithmic random variable with probability mass function given by

$$
f_{\mathrm{Z}}(\mathrm{z} ; \mathrm{p})=\frac{(1-\mathrm{p})^{\mathrm{z}}}{-\mathrm{z} \ln \mathrm{p}}, \mathrm{z} \in \square, 0<\mathrm{p}<1
$$

where,

$\mathrm{Z}$ and $\mathrm{T}_{\mathrm{i}}, \mathrm{i}=1, \ldots, \mathrm{Z}$ are independent. Let $\mathrm{X}=\min$ $\left(T_{1}, \ldots, T_{Z}\right)$ then, the pdfof the random variable $X$ is obtained as Equation 1:
$\mathrm{f}_{\mathrm{X}}(\mathrm{x} ; \mathrm{p}, \underline{\theta})=\frac{1}{-\ln \mathrm{p}} \frac{(1-\mathrm{p}) \mathrm{f}_{\mathrm{T}}(\mathrm{x} ; \underline{\theta})}{\mathrm{p}+(1-\mathrm{p}) \mathrm{F}_{\mathrm{T}}(\mathrm{x} ; \underline{\theta})}$

And hence the cumulative distribution function (cdf) of $\mathrm{X}$ is Equation 2:

$\mathrm{F}_{\mathrm{x}}(\mathrm{x} ; \mathrm{p}, \underline{\theta})=1-\frac{\operatorname{In}\left(\mathrm{p}+(1-\mathrm{p}) \mathrm{F}_{\mathrm{T}}(\mathrm{x} ; \underline{\theta})\right)}{\ln \mathrm{p}}$

The proof of the results in (1) and (2) are presented in the following theorem.

Theorem 1.1: Suppose that $T_{1}, \ldots, T_{z}$ are independent random variables with $\mathrm{f}_{\mathrm{T}_{\mathrm{i}}}(\mathrm{x}, \underline{\theta})=\mathrm{f}_{\mathrm{T}}(\mathrm{x}, \underline{\theta}), \underline{\theta}=\left(\theta_{1}, \ldots, \theta_{\mathrm{k}}\right)$ for $\mathrm{k} \geq 1, \mathrm{x}, \underline{\theta} \in \square^{+}$and $\mathrm{Z}$ is a zero truncated

Logarithmicrandom variable with probability mass function $\mathrm{f}_{\mathrm{z}}(\mathrm{z} ; \mathrm{p})=\frac{(1-\mathrm{p})^{\mathrm{z}}}{-\mathrm{z} \ln \mathrm{p}}, \mathrm{z} \in \square, 0<\mathrm{p}<1$ where $\mathrm{Z}$ and $\mathrm{T}_{\mathrm{i}, \mathrm{i}=, \ldots, \mathrm{z}}$ are independent. If $\mathrm{X}=\min \left(\mathrm{T}_{1}, \ldots, \mathrm{T}_{\mathrm{z}}\right)$ then the pdf and cdf of $\mathrm{X}$ are

$$
f_{X}(x ; p, \underline{\theta})=\frac{1}{-\ln p} \frac{(1-p) f_{T}(x ; \underline{\theta})}{p+(1-p) F_{T}(x ; \underline{\theta})}
$$

And:

$$
\mathrm{F}_{\mathrm{x}}(\mathrm{x} ; \mathrm{p}, \underline{\theta})=1-\frac{\operatorname{In}\left(\mathrm{p}+(1-\mathrm{p}) \mathrm{F}_{\mathrm{T}}(\mathrm{x} ; \underline{\theta})\right)}{\ln \mathrm{p}}
$$

Respectively.

Proof: By definition, the pdf of $\mathrm{X}$ given $\mathrm{X}=\mathrm{z}$ is:

$$
\mathrm{F}_{\mathrm{X} \mid \mathrm{Z}}(\mathrm{x} ; \underline{\theta})=\mathrm{zf}_{\mathrm{T}}(\mathrm{x} ; \underline{\theta})\left[1-\mathrm{F}_{\mathrm{T}}(\mathrm{x} ; \underline{\theta})\right]^{\mathrm{z}-1}
$$

And hence the joint pdf of $\mathrm{X}$ and $\mathrm{Z}$ is obtained as:

$$
\mathrm{F}_{\mathrm{X}, \mathrm{Z}}(\mathrm{x}, \mathrm{z} ; \mathrm{p}, \underline{\theta})=\frac{(1-\mathrm{p})^{\mathrm{z}}}{-\mathrm{z} \ln \mathrm{p}} \mathrm{zf}_{\mathrm{T}}(\mathrm{x} ; \underline{\theta})\left[1-\mathrm{F}_{\mathrm{T}}(\mathrm{x} ; \underline{\theta})\right]^{\mathrm{z}-1}
$$

The marginalpdf and cdfof $\mathrm{X}$ are given by:

$$
\begin{aligned}
& \mathrm{F}_{\mathrm{X}}(\mathrm{x} ; \mathrm{p}, \underline{\theta})=\frac{-(1-\mathrm{p}) \mathrm{f}_{\mathrm{T}}(\mathrm{x} ; \underline{\theta})}{\ln \mathrm{p}} \sum_{\mathrm{z}=1}^{\infty}\left[(1-\mathrm{p})\left(1-\mathrm{F}_{\mathrm{T}}(\mathrm{x} ; \underline{\theta})\right)\right]^{\mathrm{z}-1} \\
& =\frac{-1}{\ln \mathrm{p}} \frac{(1-\mathrm{p}) \mathrm{f}_{\mathrm{T}}(\mathrm{x} ; \underline{\theta})}{1-(1-\mathrm{p})\left(1-\mathrm{F}_{\mathrm{T}}(\mathrm{x} ; \underline{\theta})\right)} \\
& =\frac{1}{\ln \mathrm{p}} \frac{(1-\mathrm{p}) \mathrm{f}_{\mathrm{T}}(\mathrm{x} ; \underline{\theta})}{-\ln \mathrm{p} \mathrm{p}+(1-\mathrm{p}) \mathrm{F}_{\mathrm{T}}(\mathrm{x} ; \underline{\theta})}
\end{aligned}
$$

And: 


$$
\begin{aligned}
& \mathrm{F}_{\mathrm{X}}(\mathrm{x} ; \mathrm{p}, \underline{\theta})=\int_{0}^{\mathrm{x}} \mathrm{f}_{\mathrm{X}}(\mathrm{x} ; \mathrm{p}, \underline{\theta}) \mathrm{dx}=\int_{0}^{\mathrm{x}} \frac{-1}{\ln \mathrm{p}} \frac{(1-\mathrm{p}) \mathrm{f}_{\mathrm{T}}(\mathrm{x} ; \underline{\theta})}{1-(1-\mathrm{p})\left(1-\mathrm{F}_{\mathrm{T}}(\mathrm{x} ; \underline{\theta})\right)} \mathrm{dx} \\
& =1-\frac{\operatorname{In}\left(1-(1-\mathrm{p})\left(1-\mathrm{F}_{\mathrm{T}}(\mathrm{x} ; \underline{\theta})\right)\right)}{\ln \mathrm{p}} \\
& =1-\frac{\operatorname{In}\left(\mathrm{p}+(1-\mathrm{p}) \mathrm{F}_{\mathrm{T}}(\mathrm{x} ; \underline{\theta})\right)}{\ln \mathrm{p}}
\end{aligned}
$$

Respectively.

We denote a random variable $\mathrm{X}$ with pdf and cdf (1) and (2) by $\mathrm{X} \sim \operatorname{LL}(\mathrm{p}, \underline{\theta})$. Thisnew class of distributions generalizes several distributions which have been introduced and studied in the literature. For instance using the probability density and its distribution function of exponential distribution in (1), we obtain the logarithmic exponential distribution Tahmasbi and Rezaei (2008) and using Wiebull probability density and its distribution function gives Wiebulllogarithmic distribution Morais and Barreto-Souza (2011). The model is obtained under the concept of population heterogeneity (through the process of compounding). An interpretation of the proposed model is as follows: a situation where failure (of a device for example) occurs due to the presence of an unknown number, $Z$, of initial defects of same kind (a number of semiconductors from a defective lot, for example). The Ts represent their lifetimes and each defect can be detected only after causing failure, in which case it is repaired perfectly (Adamidis and Loukas, 1998). Then the distributional assumptions given earlier lead to any of the $\mathrm{L}$ Ldistributions for modeling the time to the first failure $\mathrm{X}$.

Table 1 shows the probability function and the distribution function for some lifetime distributions.

Some of the other lifetime distributions are excluded from this table such as Gamma and lognormal distributions. Those distributions do not have nice forms although they still can be applied in this class numerically.

The $q$ th quantile $x_{q}$ of the LL distribution, the inverse of the distribution function $F_{X}\left(x_{q}\right)=q$ is the same as the inverse of the distribution function $\mathrm{F}_{\mathrm{T}}\left(\mathrm{x}_{\mathrm{q}}\right)=\frac{\mathrm{p}^{1-\mathrm{q}}}{1-\mathrm{p}}$ for any continuous lifetime with distribution function $\mathrm{F}_{\mathrm{T}}$ (.).

\subsection{Survival and Hazard Functions}

Since the LL is not a part of the exponential family, there are no simple forms for moments see for instant (Kus, 2007) for the exponential case. Survival function (also known reliability function) (sf) and hazard function (known as failure rate function) (hf) for the LL class are given in the following theorem.
Theorem 1.2 Suppose that $\mathrm{T}_{1}, \ldots, \mathrm{T}_{\mathrm{z}}$ are independent random variables with $\mathrm{f}_{\mathrm{Ti}}(\mathrm{x}, \underline{\theta})=\mathrm{f}_{\mathrm{T}}(\mathrm{x}, \underline{\theta}), \underline{\theta}=$ $\left(\theta_{1}, \ldots, \theta_{\mathrm{k}}\right)$ for $\mathrm{k} \geq 1, \mathrm{x}, \underline{\theta} \in \square^{+}$and $\mathrm{Z}$ is a zero truncated Logarithmicrandom variable with probability mass function $f_{z}(z ; p)=\frac{(1-p)^{z}}{-z \ln p}, z \in \square, 0<p<1$ where $Z$ and $\mathrm{T}_{\mathrm{i}, \mathrm{i}=1, \ldots, \mathrm{z}}$ are independent. If $\mathrm{X}=\min \left(\mathrm{T}_{1}, \ldots, \mathrm{T}_{\mathrm{Z}}\right)$, then the sf and hf of $\mathrm{X}$ are Equation 3 and 4:

$$
\begin{aligned}
& \mathrm{S}_{\mathrm{X}}(\mathrm{x} ; \mathrm{p}, \underline{\theta})=\frac{\operatorname{In}\left(\mathrm{p}+(1-\mathrm{p}) \mathrm{F}_{\mathrm{T}}(\mathrm{x} ; \underline{\theta})\right)}{\operatorname{Inp}} \\
& =\frac{\operatorname{In}\left(1-(1-\mathrm{p}) \mathrm{S}_{\mathrm{T}}(\mathrm{x} ; \mathrm{p}, \underline{\theta})\right)}{\operatorname{Inp}}
\end{aligned}
$$

And:

$$
\begin{aligned}
& \mathrm{h}_{\mathrm{x}}(\mathrm{x} ; \mathrm{p}, \underline{\theta})=\frac{-(1-\mathrm{p}) \mathrm{f}_{\mathrm{T}}(\mathrm{x} ; \underline{\theta})}{\left(\mathrm{p}+(1-\mathrm{p}) \mathrm{F}_{\mathrm{T}}(\mathrm{x} ; \underline{\theta})\right) \operatorname{In}\left(\mathrm{p}+(1-\mathrm{p}) \mathrm{F}_{\mathrm{T}}(\mathrm{x} ; \underline{\theta})\right)} \\
& =\frac{-(1-\mathrm{p}) \mathrm{f}_{\mathrm{T}}(\mathrm{x} ; \underline{\theta})}{\left(1-\left((1-\mathrm{p}) \mathrm{S}_{\mathrm{T}}(\mathrm{x} ; \mathrm{p}, \underline{\theta})\right)\right) \operatorname{In}\left(1-(1-\mathrm{p}) \mathrm{S}_{\mathrm{T}}(\mathrm{x} ; \mathrm{p}, \underline{\theta})\right)}
\end{aligned}
$$

Respectively.

Proof: Using (1) and (2), survival function (also known reliability function) and hazard function (known as failure rate function) for the LL class are given respectively by:

$$
\begin{aligned}
& \mathrm{S}_{\mathrm{X}}(\mathrm{x} ; \mathrm{p}, \underline{\theta})=1-\mathrm{F}_{\mathrm{X}}(\mathrm{x} ; \mathrm{p}, \underline{\theta})=1-\left(1-\frac{\operatorname{In}\left(\mathrm{p}+(1-\mathrm{p}) \mathrm{F}_{\mathrm{T}}(\mathrm{x} ; \underline{\theta})\right)}{\ln \mathrm{p}}\right) \\
& \left.=\frac{\operatorname{In}\left(\mathrm{p}+(1-\mathrm{p}) \mathrm{F}_{\mathrm{T}}(\mathrm{x} ; \underline{\theta})\right)}{\ln \mathrm{p}}\right) \\
& \left.=\frac{\operatorname{In}\left(1-(1-\mathrm{p}) \mathrm{S}_{\mathrm{T}}(\mathrm{x} ; \mathrm{p}, \underline{\theta})\right)}{\ln \mathrm{p}}\right)
\end{aligned}
$$

And:

$$
\begin{aligned}
& \mathrm{h}_{\mathrm{x}}(\mathrm{x} ; \mathrm{p}, \underline{\theta})=\frac{\mathrm{f}_{\mathrm{X}}(\mathrm{x} ; \mathrm{p}, \underline{\theta})}{\mathrm{s}_{\mathrm{x}}(\mathrm{x} ; \mathrm{p}, \underline{\theta})} \\
& =\frac{-(1-\mathrm{p}) \mathrm{f}_{\mathrm{T}}(\mathrm{x} ; \underline{\theta})}{\left(1-\left(1-\mathrm{p}\left(1-\mathrm{F}_{\mathrm{T}}(\mathrm{x} ; \underline{\theta})\right)\right) \operatorname{In}\left(-1\left(1-\mathrm{p}\left(1-\mathrm{F}_{\mathrm{T}}(\mathrm{x} ; \underline{\theta})\right)\right)\right.\right.} \\
& =\frac{-(1-\mathrm{p}) \mathrm{F}_{\mathrm{T}}(\mathrm{x} ; \underline{\theta})}{\left(\mathrm{p}+(1-\mathrm{p}) \mathrm{F}_{\mathrm{T}}(\mathrm{x} ; \underline{\theta})\right) \operatorname{In}\left(\mathrm{p}+(1-\mathrm{p}) \mathrm{F}_{\mathrm{T}}(\mathrm{x} ; \underline{\theta})\right)} \\
& =\frac{-(1-\mathrm{p}) \mathrm{f}_{\mathrm{T}}(\mathrm{x} ; \underline{\theta})}{\left(1-(1-\mathrm{p}) \mathrm{s}_{\mathrm{T}}(\mathrm{x} ; \mathrm{p}, \underline{\theta})\right) \operatorname{In}\left(1-(1-\mathrm{p}) \mathrm{s}_{\mathrm{T}}(\mathrm{x} ; \mathrm{p}, \underline{\theta})\right)}
\end{aligned}
$$

where, $\left(\mathrm{S}_{\mathrm{T}}(\mathrm{z} ; \underline{\theta})\right)$ is the survival function of any continuous lifetime distribution. 
Table 1. Probability and distribution functions

\begin{tabular}{llc}
\hline & $\mathrm{f}_{\mathrm{x}}(\mathrm{x} ; \mathrm{p}, \underline{\theta})$ & $\mathrm{F}_{\mathrm{x}}(\mathrm{x} ; \mathrm{p}, \underline{\theta})$ \\
\hline Exponential & $\frac{1}{-\operatorname{In} \mathrm{p}} \frac{(1-\mathrm{p}) \lambda \mathrm{e}^{-\lambda \mathrm{x}}}{1-(1-\mathrm{p}) \mathrm{e}^{-\lambda \mathrm{x}}}$ & $1-\frac{\operatorname{In}\left(1-(1-\mathrm{p}) \mathrm{e}^{-\lambda x}\right)}{\operatorname{Inp}}$ \\
Weibull & $\frac{1}{\operatorname{In} \mathrm{p}} \frac{\lambda(1-\mathrm{p})(\lambda \mathrm{x})^{\mathrm{a}-1} \mathrm{e}^{-(\lambda x) \mathrm{a}}}{1-(1-\mathrm{p}) \mathrm{e}^{-(\lambda x) \mathrm{a}}}$ & $1-\frac{\operatorname{In}\left(1-(1-\mathrm{p}) \mathrm{e}^{-(\lambda x)^{\mathrm{a}}}\right)}{\operatorname{Inp}}$ \\
Rayleigh & $\frac{1}{-\theta^{2} \operatorname{In} \mathrm{p}} \frac{(1-\mathrm{p}) \mathrm{x}^{\frac{\mathrm{e}^{2}}{2 \theta^{2}}}}{1-(1-\mathrm{p}) \mathrm{e}^{-\frac{\mathrm{x}^{2}}{2 \theta^{2}}}}$ & $\operatorname{In}\left(1-(1-\mathrm{p}) \mathrm{e} \frac{\mathrm{x}^{2}}{2 \theta^{2}}\right)$ \\
Pareto & $\frac{1}{\operatorname{In}} \frac{(1-\mathrm{p}) \gamma}{(1+\mathrm{x})^{\gamma+1}-(1-\mathrm{p})(1+\mathrm{x})}$ & $1-\frac{\operatorname{In}\left(1-(1-\mathrm{p})(1+\mathrm{x})^{-\gamma}\right)}{\operatorname{Inp}}$ \\
\hline
\end{tabular}

Table 2. Survival and hazard functions

\begin{tabular}{|c|c|c|}
\hline & $\mathrm{s}_{\mathrm{x}}(\mathrm{x} ; \mathrm{p}, \underline{\theta})$ & $\mathrm{h}_{\mathrm{x}}(\mathrm{x} ; \mathrm{p}, \underline{\theta})$ \\
\hline Exponential & $\frac{\operatorname{In}\left(1-(1-p) e^{-\lambda x}\right)}{\operatorname{In} p}$ & $\frac{-(1-p) \mathrm{e}^{-\lambda x}}{\left(1-(1-p) \mathrm{e}^{-\lambda x}\right) \operatorname{In}\left(\left(1-(1-p) \mathrm{e}^{-\lambda x}\right)\right.}$ \\
\hline Weibull & $\frac{\operatorname{In}\left(1-(1-p) e^{-(\lambda x)^{a}}\right)}{\operatorname{In} p}$ & $\frac{-(1-p) \mathrm{e}^{-(\lambda x)^{a}}}{\left(1-(1-p) \mathrm{e}^{-(\lambda x) a}\right) \operatorname{In}\left(1-(1-p) \mathrm{e}^{-(\lambda x)^{a}}\right)}$ \\
\hline \multirow[t]{2}{*}{ Rayleigh } & $\frac{\ln \left(1-(1-p) e^{\frac{x^{2}}{2^{\theta^{2}}}}\right)}{\operatorname{Inp}}$ & $-(1-p) e^{\frac{x^{2}}{2 \theta^{2}}}$ \\
\hline & & $\left(1-(1-p) e \frac{x^{2}}{2 \theta^{2}}\right) \operatorname{In}\left(1-(1-p) e^{\frac{x^{2}}{2 \theta^{2}}}\right)$ \\
\hline \multirow[t]{2}{*}{ Pareto } & $\underline{\operatorname{In}\left(1-(1-p)(1+x)^{-\gamma}\right)}$ & $\gamma$ \\
\hline & Inp & {$\left[(1+x)-(1-p)^{-1}(1+x)^{\gamma+1}\right] \operatorname{In}\left(1-(1-p)(1+x)^{-\gamma}\right)$} \\
\hline
\end{tabular}

Table 2 summarizes the survival functions and hazard rate functions for some distributions of the class.

\subsection{Estimation}

In what follows, we discuss the estimation of the LL class parameters. Let $\mathrm{x}_{1}, \ldots, \mathrm{x}_{\mathrm{n}}$ be a random sample with observed values $\mathrm{x}_{1}, \ldots, \mathrm{x}_{\mathrm{n}}$ from a $\mathrm{L}$ Ldistribution with parameters $p$ and $\underline{\theta}$. Let $\Theta=(p, \underline{\theta})$ be the parameters vector. The log log-likelihood function based on the observed random sample size of $\mathrm{n}, \mathrm{y}_{\mathrm{obs}}=\left(\mathrm{x}_{1}, \ldots, \mathrm{x}_{\mathrm{n}}\right)$ is obtained by:

$$
\begin{aligned}
& \ell\left(\mathrm{p}, \underline{\theta} ; \mathrm{y}_{\mathrm{obs}}\right)=\mathrm{n} \log (1-\mathrm{p})-\mathrm{n} \log (-\log \mathrm{p})+\sum_{\mathrm{i}=1}^{\mathrm{n}} \log \mathrm{f}_{\mathrm{T}}\left(\mathrm{x}_{\mathrm{i}} ; \underline{\theta}\right) \\
& +\sum_{\mathrm{i}=1}^{\mathrm{n}} \log \left(\mathrm{x}_{\mathrm{i}} ; \underline{\theta}\right)+\sum_{\mathrm{i}=1}^{\mathrm{n}} \log \left(\mathrm{p}+(1-\mathrm{p}) \mathrm{F}_{\mathrm{T}}\left(\mathrm{x}_{\mathrm{i}} ; \underline{\theta}\right)\right)
\end{aligned}
$$

And the associated score function is given by $\mathrm{U}_{\mathrm{n}}(\Theta)=\left(\frac{\partial \ell}{\partial \mathrm{p}}, \frac{\partial \ell}{\partial \theta_{1}}, \ldots, \frac{\partial \ell}{\partial \theta_{\mathrm{k}}}\right)^{\mathrm{T}}$, where Equation 5 and 6 :

$$
\begin{aligned}
& \frac{\partial \ell(\mathrm{p}, \underline{\theta} ; \text { yobs })}{\partial \mathrm{p}} \\
& =\frac{\mathrm{n}}{1-\mathrm{p}}-\frac{\mathrm{n}}{\mathrm{p} \log \mathrm{p}}-\sum_{\mathrm{i}=1}^{\mathrm{n}} \frac{\mathrm{F}_{\mathrm{T}}\left(\mathrm{x}_{\mathrm{i}} ; \underline{\theta}\right)}{\mathrm{p}+(1-\mathrm{p}) \mathrm{F}_{\mathrm{T}}\left(\mathrm{x}_{\mathrm{i}} ; \underline{\theta}\right)}
\end{aligned}
$$

And:

$$
\begin{aligned}
& \frac{\partial \ell(\underline{\theta} ; \text { yobs })}{\partial \mathrm{p}}=\sum_{\mathrm{i}=1}^{\mathrm{n}} \frac{1}{\mathrm{f}_{\mathrm{T}}\left(\mathrm{x}_{\mathrm{i}} ; \underline{\theta}\right)} \frac{\partial \mathrm{f}_{\mathrm{T}}\left(\mathrm{x}_{\mathrm{i}} ; \underline{\theta}\right)}{\partial \theta_{\mathrm{i}}} \\
& +\sum_{\mathrm{i}=1}^{\mathrm{n}} \frac{1-\mathrm{p}}{\mathrm{p}+(1-\mathrm{p}) \mathrm{F}_{\mathrm{T}}\left(\left(\mathrm{x}_{\mathrm{i}} ; \underline{\theta}\right)\right.} \frac{\partial \mathrm{f}_{\mathrm{T}}\left(\mathrm{x}_{\mathrm{i}} ; \underline{\theta}\right)}{\partial \theta_{\mathrm{i}}}, \mathrm{i}=1, \ldots, \mathrm{k}
\end{aligned}
$$

The Maximum Likelihood Estimates(MLE) of $\Theta$, say $\Theta$, is obtained by solving the nonlinear system $U_{n}(\Theta)=$ OThe solution of this nonlinear system of equations has not a closed form, but can be found numerically by using software such as MATHEMATICA, MAPLE, Ox and R.

For interval estimation and hypothesis tests on the model parameters, we require the information matrix. The $(\mathrm{k}+1) \times(\mathrm{k}+1)$ information matrix is given by:

$$
I_{n}(\Theta)=\left(\begin{array}{cc}
1_{p p} & 1_{p \theta_{i}} \\
l_{\theta_{i} p} & 1_{\theta_{i} \theta_{i}}
\end{array}\right)
$$

where, the elements of In $(\Theta)$ are the second partial derivatives of (5) and (6). Under the regular conditions 
stated in Cox and Hinkley (1974), that are fulfilled for our model whenever the parameters are in the interior of the parameter space, we have that the asymptotic distribution of $\sqrt{\mathrm{n}}(\Theta-\Theta)$ is multivariate normal $\mathrm{N}_{\mathrm{k}+1}\left(0, \mathrm{k}(\Theta)^{-1}\right)$, where $\mathrm{k}(\Theta)-\lim _{\mathrm{n} \rightarrow \infty} \mathrm{n}^{-1} / \mathrm{n}(\Theta)$ is the unit information matrix.

\subsection{EM algorithm}

Based on the underlying distribution, the maximum likelihood estimation of the parameters can be found analytically using an EM algorithm. Newton-Raphson algorithm is one of the standard methods to determine the MLEs of the parameters. To employ the algorithm, second derivatives of the log-likelihood are required for all iteration. EM algorithm is a very powerful tool in handling the incomplete data problem (Dempster et al., 1977; McLachlan and Krishnan, 1997). It is an iterative method by repeatedly replacing the missing data with estimated values and updating the parameter estimates. It is especially useful if the complete data set is easy to analyze. As pointed out by Little and Rubin (1983), the EM algorithm will converge reliably but rather slowly (as compared to the Newton-Raphson method) when the amount of information in the missing data is relatively large. Recently, EM algorithm has been used by several authors such as Adamidis and Loukas (1998); Adamidis (1999); $\mathrm{Ng}$ et al. (2002); Karlis (2003); Adamidis et al. (2005).

To estimate $\Theta$, EM algorithm is a recurrent method such that each step consists of an estimate of the expected value of a hypothetical random variable and later maximizes the log-likelihood of the complete data. Let the complete data be $X_{1}, \ldots, X_{n}$ with observed values $x_{1}, \ldots, x_{n}$ and the hypothetical random variable $Z_{1}, \ldots, Z_{n}$. The joint probability function is such that the marginal density of $X_{1}, \ldots, X_{n}$ is the likelihood of interest. Then, we define a hypothetical complete-data distribution for each $\left(X_{i}, Z_{i}\right)^{T}, i+1, \ldots, n$.

With a joint probability function in the form:

$$
f_{X, Z}(X, Z ; \Theta)=\frac{(1-p)^{z}}{-z \ln p} z f_{T}(x ; \underline{\theta})\left[1-F_{T}(x ; \underline{\theta})\right]^{z-1}
$$

With $\quad \mathrm{x}, \underline{\theta} \in \square^{+}, 0<\mathrm{p}<1$ and $\mathrm{z} \in \square$. Thus, it is straightforward to verify that the Estep of an EM cycle requires the computation of the conditional expectation of $\left(z \mid x ; \Theta^{(\gamma)}\right)$, where $\Theta^{(\gamma)}=\left(P^{(\gamma)}, \underline{\theta}^{(\gamma)}\right)$ is the current estimate (in the rth iteration) of $\Theta$. The EM cycle is completed with M-step, which is complete data maximum likelihood over $(\Theta)$, with the missing Z's replaced by their conditional expectations $\mathrm{E}(\mathrm{z} \mid \mathrm{x} ; \Theta)$ (Adamidis and Loukas, 1998), where:

$$
\mathrm{f}_{\mathrm{Z} \mid \mathrm{X}}(\mathrm{z})=\left[(1-\mathrm{p})\left(1-\mathrm{F}_{\mathrm{T}}(\mathrm{x} ; \underline{\theta})\right)\right]^{\mathrm{z}-1}\left[1-(1-\mathrm{p})\left(1-\mathrm{F}_{\mathrm{T}}(\mathrm{x} ; \underline{\theta})\right)\right]
$$

And its expected value is:

$$
E(Z \backslash X)=\frac{(1-p)\left(1-F_{T}(x ; \underline{\theta})\right)}{1-(1-p)\left(1-F_{T}(x ; \underline{\theta})\right)}
$$

\subsection{Entropy for the Class}

If $\mathrm{X}$ is a random variable having an absolutely continuous cumulative distribution function $F_{X}(x)$ and probability distribution function $f_{x}(x)$ then the basic uncertainty measure for distribution $\mathrm{F}$ (called the entropy of F) is defined as Equation 7:

$$
\begin{aligned}
& \mathrm{H}_{\mathrm{X}}(\mathrm{X})=-\mathrm{E}(\log \mathrm{f}(\mathrm{x}))=\log (-\log \mathrm{p})-\log (1-\mathrm{p})+\frac{1-\mathrm{p}}{\log \mathrm{p}} \\
& \int_{0}^{\infty} \frac{\mathrm{f}_{\mathrm{T}}\left(\mathrm{x}_{\mathrm{i}} ; \underline{\theta}\right)}{1-(1-\mathrm{p}))\left(1-\mathrm{F}_{\mathrm{T}}(\mathrm{x} ; \underline{\theta})\right)} \log \frac{\mathrm{f}_{\mathrm{T}}\left(\mathrm{x}_{\mathrm{i}} ; \underline{\theta}\right)}{1-(1-\mathrm{p}))\left(1-\mathrm{F}_{\mathrm{T}}(\mathrm{x} ; \underline{\theta})\right)} \mathrm{dx}
\end{aligned}
$$

Note that as $\mathrm{p}$ increases the $\mathrm{H}_{\mathrm{X}}(\mathrm{X})$ increases too which is very logical since the increase of probability of accidents increases the entropy

Statistical entropy is a probabilistic measure of uncertainty or ignorance about the outcome of a random experiment and is a measure of a reduction in that uncertainty. Since Shannon (1948) pioneering work on the mathematical theory of communication, entropy (7) has been used as a major tool in information theory and in almost every branch of science and engineering. Numerous entropy and information indices, among them the Renyi entropy, have been developed andused in various disciplines and contexts. Information theoretic principles and methods have become integral parts of probability and statistics and have been applied in various branches of statistics and related fields.

\section{ACKNOWLEDGEMENT}

The author is highly grateful to the deanship of scientific research at King Saud University represented by the research center at college of business administration for supporting this research financially.

\section{REFERENCES}

Adamidis, K. and S. Loukas, 1998. A lifetime distribution with decreasing failure rate. Stat. Probability Lett., 39: 35-42. DOI: 10.1016/S01677152(98)00012-1 
Adamidis, K., 1999. An EM algorithm for estimating negative binomial parameters. Austral. New Zealand Stat., 41: 213-221. DOI: 10.1111/1467-842X.00075

Adamidis, K., T. Dimitrakopoulou and S. Loukas, 2005. On an extension of the exponential-geometric distribution. Stat. Probab. Lett. 73, 259-269. DOI: 10.1016/j.spl.2005.03.013

Alkarni, S. and A. Oraby, 2012. A compound class of poisson and lifetime distributions. J. Stat. Applied Pro., 1: 45-51.

Barreto-Souza, W. and F. Cribari-Neto, 2009. A generalization of the exponential-Poisson distribution. Stat. Probability Lett., 79: 2493-2500. DOI: $10.1016 /$ j.spl.2009.09.003

Chahkandi, M. and M. Ganjali, 2009. On some lifetime distributions with decreasing failure rate. Comput. Stat. Data Anal., 53: 4433-4440. DOI: 10.1016/j.csda.2009.06.016

Cox, D.R. and D.V. Hinkley, 1974. Theoretical Statistics. 1st Edn., Chapman and Hall, London.

Dempster, A.P., N.M. Laird and D.B. Rubin, 1977. Maximum likelihood from incomplete data via the EM algorithm. J. Roy. Stat. Soc. Ser. B, 39: 1-38. DOI: $10.2307 / 2984875$

Gleser, L.J., 1989. The gamma distribution as a mixture of exponential distributions. Am. Stat., 43: 115-117.

Gurland, J. and J. Sethuraman, 1994. Reversal of increasing failure rates when pooling failure data. Technometrics, 36: 416-418.

Hemmati, F., E. Khorram and S. Rezakhah, 2011. A new three-parameter ageing distribution. J. Stat. Plann. Inference, 141: 2255-2275. DOI: 10.1016/j.jspi.2011.01.007

Karlis, D., 2003. An EM algorithm for multivariate Poisson distribution and related models. J. Applied Stat., 30: 63-77. DOI: 10.1080/0266476022000018510

Kus, C., 2007. A new lifetime distribution. Comput. Stat. Data Anal., 51: 4497-4509. DOI: 10.1016/j.csda.2006.07.017

Little, R.J.A. and D.B. Rubin, 1983. Incomplete Data. In: Encyclopedia of Statistical Sciences, Kotz, S., Johnson, N.L. (Eds.), Wiley, NewYork.

Lomax, K.S., 1954. Business failures: Another example of the analysis of failure data. J. Am. Stat. Assoc., 49: 847-852.

McLachlan, G.J. and T. Krishnan, 1997. The EM Algorithm and Extension. 1st Edn., Wiley, NewYork.

McNolty, F., J. Doyle and E. Hansen, 1980. Properties of the mixed exponential failure process. Technometrics, 22: 555-565.
Morais, A. and W. Barreto-Souza, 2011. A compound class of Weibull and power series distributions. Comput. Stat. Data Anal., 55: 1410-1425. DOI: 10.1016/j.csda.2010.09.030

Morais, A., 2009. A class of generalized beta distributions, pareto power series and weibull power series. M.Sc Thesis, Universidade Federal de Pernambuco.

Mudholkar, G.S. and A.D. Hutson, 1996. The exponentiated weibull family: Some properties and a flood data application. Commun. Stat. Theory Methods, 25: 3059-3083. DOI: 10.1080/03610929608831886

Mudholkar, G.S. and D.K. Srivastava, 1993. Exponentiated Weibull family for analyzing bathtub failure-rate data. IEEE Trans. Reliab., 42: 299-302. DOI: 10.1109/24.229504

Mudholkar, G.S., D.K. Srivastava and M. Freimer, 1995. The exponentiated weibull family: A reanalysis of the bus-motor-failure data. Technometrics, 37: 436-445.

Nadarajah, S. and S. Kotz, 2006. On the product and ratio of gamma and weibull random variables. Econ. Theory, 22: 338-344. DOI: $10.1017 / \mathrm{S} 0266466606060154$

Nassar, M.M. and F.H. Eissa, 2003. On the exponentiated weibull distribution. Commun. Stat. Theory Methods, 32: 1317-1336. DOI: 10.1081/STA-120021561

Ng, H.K.T., P.S. Chan and N. Balakrishnan, 2002. Estimation of parameters from progressively censored data using EM algorithm. Comput. Stat. Data Anal., 39: 371-386. DOI: 10.1016/S01679473(01)00091-3

Proschan, F., 1963. Theoretical explanation of observed decreasing failure rate. Technometrics, 5: 375-383. DOI: $10.2307 / 1266340$

Saunders, S.C. and J.M. Myhre, 1983. Maximum likelihood estimation for two-parameter decreasing hazard rate distributions using censored data. J. Am. Stat. Assoc., 78: 664-673. DOI: 10.1080/01621459.1983.10478027

Shannon, C.E., 1948. A mathematical theory of communication. Bell Syst. Technical J., 27: 379-432.

Silva, R.B., W. Barreto-Souza and G.M. Cordeiro, 2010. A new distribution with decreasing, increasing and upside-down bathtub failure rate. Comput. Stat. Data Anal., 54: 935-944. DOI: 10.1016/j.csda.2009.10.006

Tahmasbi, R. and S. Rezaei, 2008. A two-parameter lifetime distribution with decreasing failure rate. Comput. Stat. Data Anal., 52: 3889-3901. DOI: 10.1016/j.csda.2007.12.002 